\title{
Determinants of Household Energy Demand in Ethiopia: The Case Study of Addis Ababa City
}

\author{
Getamesay Bekele ${ }^{1}$, Workneh Negatu ${ }^{2} \&$ Getachew Eshete $^{3}$ \\ ${ }^{2}$ College of Development Studies, Addis Ababa University, Addis Ababa, Ethiopia. \\ ${ }^{3}$ DFID Ethiopia, Addis Ababa, Ethiopia. \\ Correspondence: Getamesay Bekele, School of Economics, Debre Berhan University, Debre Berhan, Ethiopia.
}

Received: June19, 2015

doi:10.11114/aef.v3i1.1193
Accepted: July 9, $2015 \quad$ Available online: November 10, 2015

URL: http://dx.doi.org/10.11114/aef.v3i1.1193

\begin{abstract}
This paper analyzes the household energy demand in Ethiopia: the case study of Addis Ababa City. The weighted average income of energy is used to estimate the energy demand in the city, using cross sectional data from 466 households in 2012/13. The result indicates that each household spends on average $14.7 \%$ or 376.98 birr per month of its expenditure for energy purchase from their total expenditure is 2760.84 birr. Household energy demand is estimated by the share of energy expenditure from total household expenditure. Energy is a necessity good for city households and has positive income elasticity $(+0.61)$. And, household size, the proportion of women in households, household head level of education, owning of dwelling and electric appliance (electric meter and refrigerator) are important underpinning factors that affect the decision to use a particular energy type. Thus, improving access to different energy sources especially the modern ones are essential to increase household modern energy demand and reduce energy poverty in city.
\end{abstract}

Keywords: Energy demand, Access, Necessity, Energy poverty

\section{Introduction}

\subsection{Background of the Study}

Energy is one of the basic elements of economic and social development. It contributes to health and education service delivery, and helps to meet the basic human needs such as food and shelter (IEA, 2010). There are traditional and modern energy sources. Traditional energy sources are firewood, charcoal, crop residues and animal waste. They are also referred as biomass energy and are obtained from natural environment. The modern energy sources are kerosene, Liquid Petroleum Gas (LPG) and electricity. These energy sources are collectively termed as modern or commercial energy sources (Leach, 1987). Modern energy services have important role in improving production and productivity. They relieve millions of women and children from daily burden of water fetching and firewood collection. They can help to extend the working time, increase individual income, invest children's time in schooling and deliver health services to the community (World Bank, 2000).

The number of people who depends on traditional energy sources in the world is estimated to be 2.7 billion of the global population in 2009. Among these, 2.6 billion people are from developing countries, 653 million people of which are from Sub-Saharan Africa. In case of Ethiopia, more than 67 million people are dependent on biomass energy to meet their cooking, heating, lighting and hygiene needs (UNDP, 2009; IEA, 2010; DGEP, 2011; and CSA, 2012). This dependency on traditional energy sources in developing countries in general and sub-Saharan Africa countries in particular is creates the energy poverty. Energy poverty refers to the households that spend more than $10 \%$ of their income on fuel to maintain an adequate level of energy (Masud, et.al, 2007). The term also refers to the absence of sufficient choices in accessing, affordable, reliable, high quality, safe and environmentally benign energy services to support economic and human development (Kemmler, 2007).).

For example: $61 \%$ of the Indian, $84 \%$ of the Cambodian, $73 \%$ of the Kenyan, $84 \%$ of the Tanzanian and $90 \%$ of the Ethiopian population are energy poor. In these countries, many people have no access to efficient and clean energy sources for domestic energy use (ESCAP, 2012).

Regarding access to electricity, 1.32 billion people in the world lacks access to electricity. From this, 1.3 billion people 
are from developing countries, of which 586 million people are from Sub-Saharan Africa. In Ethiopia, more than 46 million people live without access to electricity. Generally, $51 \%$ of the population of developing countries, $78 \%$ of the Sub-Saharan African population and 93\% of Ethiopian population use biomass energy for their domestic use. Moreover, $25 \%$ of developing countries population, 69\% of Sub-Saharan African countries population and $63 \%$ of Ethiopian population have no access to electricity (UNDP, 2009; IEA, 2010; DGEP, 2011; and EPA, 2012). However, such heavy dependency on biomass energy sources creates deforestation, land degradation, soil erosion, climate change and energy poverty in those countries (World Bank, 2000; Alemu, et. al, 2008; and Yonas, et. al., 2013).

Besides, the use of traditional and modern energy sources has enormous impact on social and economic development and overall quality of life of the population. This energy demand is affected by many factors like energy price, household income, stocks of energy sources, population, level of urbanization, family size, level of technology and overall development and structure of the economy, etc. at macro and micro level are amongst the major ones to be mentioned (World Bank, 2000). The demand for energy at micro level means: household energy use at the family level is affected by different socio-economic factors like income, price, family size, education, technology, accessibility, etc.

\subsection{Literature Review}

We critically reviewed different empirical studies, which have been used in the analysis of household energy demand in different developing countries including Ethiopia. The demand for various sources of energy has been analyzed theoretically and empirically by using different models by different scholars. Different studies were made by Leach (1992), Hydy,et.al. (2000), Bereket,et.al., (2002), ESMAP (2003), Heltberg (2003), Chambwera (2004), Ouedraogo (2006), Kemmler (2007), Zenebe (2007), Alemu,et.al. (2008), Samuel (2008), Getamesay (2011), Nyembe (2011), Dawit (2012), Mekonen (2012), Nnaji,et,al. (2012) and Yonas,et.al. (2013). Those studies listed above considered different factors to determine household energy demand at micro and macro levels. Among different empirical studies, the following are the main ones:

Leach (1992) examined household energy demand in different South Asian countries like Indonesia, Malaysia, Sri Lanka and Colombo and India. The finding indicated that the price of LPG was relatively expensive compare to kerosene and it was the second most important factor after equipment cost. Besides, other factors like family size, local cooking practices were affection the energy consumption. He also examined the speed and extent of fuel switching along the energy ladder models with estimating several factors like physical access, equipment costs, income and relative fuel prices. According to his finding, the appliance cost hindered households from switching upwards to modern energy. For example, in Sri Lanka and Colombo, the LPG appliance cost equal to at least one month's income for $70 \%$ of households and three months' income for poorest households (12\%).

Hydy, et.al. (2000) conducted a comprehensive study on the effect of own price of fire wood in rural Indian household energy demand. The work indicated that demand for fire wood was inversely related to own price. They also examined the income elasticity of fuel, households' consumption pattern and demand for energy in urban areas. They concluded that the income, family size, education and level of urbanization had positive impact on the uses fire wood. According to them, the owners of refrigerator households assessed during the study consumed less energy (fire wood, charcoal, kerosene and LPG) than the household without refrigerator. The reason behind less consumption of fuels were less cooking frequency due to preserved cooked food in refrigerator for long time.

Bereket, et al. (2002) carried out a study to examine the demand of modern fuels (electricity, LPG and Kerosene) by the urban poor in Ethiopia. They examined different factors that affected for energy demand. In the study, they estimated the price and income elasticity of energy by a multivariate analysis. The factors were the budget share of each fuel, price of fuels and household size. According to their finding, all fuels had positive income elasticity and the price elasticity of each fuel was negative. Also, poor households generally spent more money for energy than rich households and the high energy costs had a large budgetary implication for the poor. Besides, they found out that the non-poor households spent relatively more on modern energy as compared to traditional energy sources than the poor.

Energy Sector Management Assistance Program (ESMAP, 2003) studied the Latin American household energy demand. The study found different factors that affect energy demand in urban areas of Guatemala and Brazil. The factors are energy price, household income and family size. According to their findings; poor households used different fuels simultaneously as their income rose. Households also adopted the multiple fuel strategy for different reasons. First, households often have invested significant capital in traditional technologies (e.g. fire wood burning stoves) and could not have the spare capital to buy new energy appliances, immediately up on gaining access to new energy sources. Secondly, modern energy sources were expensive and applied carefully for unique services such as radio, television and refrigerators etc.

Heltberg (2003) analyzed the household energy demand in eight developing countries (Brazil, Ghana, Guatemala, Indian, Nepal, Nicaragua South Africa and Vietnam,). The main findings were: own price of fuel was inversely affected 
the energy demand. Income had a positive impact on household fuel switching in the energy ladder. There are large important differences between countries in the cooking fuel mix, between solid and non-solid and within the group of solid fuels. Non solid fuels were normal goods in these countries households and fire wood, animal dung and straw were inferior fuels.

Chambwera (2004) conducted research on economic analysis of urban fire wood demand in Harare, Zimbabwe. He investigated the demand for energy with energy mix model. He employed a multi-stage budgeting approach to estimate the proportion of total household expenditure for energy, food and other goods in the first stage and then estimated proportion of energy budget spent on each types of fuel in the second stage. He considered the Almost Ideal Demand System (AIDS) model for energy demand estimation and used the Probit model to test energy choices of households by classifying them as un-electrified and electrified households. According to his findings, the share of energy expenditures was $13 \%$ for electrified and $11 \%$ for un-electrified households from total expenditure. For all households (electrified and un- electrified), total energy expenditure rose proportionally with the increase of total household expenditure rose. Furthermore, household size, energy appliances owned, price of fuels, income, the number of rooms used by the household and family head education level were the main determinants factor of energy demand. He also found that high level of family head education had a positive impact on using of more modern energy sources than traditional energy ones. Besides, the households with large family members, they used more kinds or mixes of fuel.

Ouedraogo (2006) examined household energy cooking preference in urban Ouagadougou, the capital city of Burkina Faso by using a multinomial logit model. He tried to identify different variables like household size, age, sex, level of education, marital status, religion, owning of refrigerator, electric meter, owning of dwelling, etc. for household energy demand. According to his finding, family size and consumption of energy had positive relationship. Household head with old age used more traditional energy than modern energy and Female headed households were more likely to use firewood than male headed households. Households with less educational level used more traditional energy than the modern ones. The married households preferred to use fire wood and kerosene than charcoal as compared to not married households. Since they require more alternative energy mixes for cooking and baking to feed their members. Besides, owning refrigerator had a negative impact on consumption of energy or cooking frequencies. Own electric meter also had a negative impact on consumption of other energy type except electricity and owning of dwelling had also a positive impact on the consumption of fire wood than any others fuels.

Kemmler (2007) conducted research on the characteristics of energy access in Indian regions. He used the two dimensional energy poverty measurement approaches (economic and access to energy poverty measurement approach). According to his findings, $20 \%$ to $30 \%$ of the households' income went to energy consumption. He also identified other factors like prices of energy, sex, family size, education level of family head and accessibility to modern energy sources.

Zenebe (2007) made the study of household fuel consumption and resources use in rural -urban Ethiopia in Tigray region. He chosen the appropriate functional form of energy demand and handled zero expenditure (problem of censored data) by employing Heckman's two-step estimation. In the first step, he employed the probit model to capture the decision of households whether or not to choose the specific fuel. In the second step, he incorporated the inverse mill's ratio generated and incorporated in to the second step estimation of AIDS to account for bias in sample selection. According to his finding, electricity and firewood, kerosene and charcoal were substitute's fuels and all fuel types were price inelastic. While, electricity was found to be luxury (i.e. with expenditure elasticity of greater than one), other energy goods were necessity goods. Besides, family sizes, age and education of family head were important variables in the household's decision to consume a particular energy sources, but the relative importance of each factors varied from one fuel to another.

Alemu, et.al. (2008) examined the determinants of household fuel choice in major cities in Ethiopia. In their finding, the proportion of households using fire wood, charcoal, kerosene and electricity was between 40 to $80 \%$ for all expenditure categories. They also found, households in the urban areas had tended to increase the number of fuels as their income rose instead of completely switching from consumption of traditional fuels such as fire wood to modern ones such as kerosene and electricity. They found that households with old age heads were more likely to use fire wood and kerosene than charcoal and electricity. Female headed households were more likely to use fire wood than charcoal while charcoal consumption was higher in male headed households. They also tried to link the level of education with using of energy and found that the household heads with the high level of education in secondary or post-secondary schools had high probability of consuming clean fuels (kerosene and electricity) than fire wood and charcoal.

Samuel (2008) analyzed the energy demand for urban Ethiopia and found that price, income level and availability of different fuel types were the major factors to determine the consumption patterns of urban households. According to him, household size had positive effect on energy demand and is more pronounced in the use of traditional energy sources. Using the multivariate probit model analysis, he estimated the probability of choosing modern and traditional energy sources. According to his findings, as household income increases, the probability of choosing modern fuel also 
rises than the traditional fuel. From the finding, he had also determined the price elasticity of charcoal, firewood and kerosene consumption found all were price elastic. Also, the cross-price elasticity of kerosene and firewood, kerosene and charcoal were negative Both finding indicated that the fuels were complementary fuels. Besides, all fuel types are necessary goods because of their income elasticities were positive and below one for charcoal, kerosene, firewood and electricity respectively.

Getamesay (2011) attempted to examine determinants of kerosene and LPG demand in Ethiopia using time series data. Real price of kerosene, real price of LPG, real per capita income and real foreign exchange earnings were found to be significantly affecting demand for kerosene and real price of LPG, real price of kerosene, population growth, level of urbanization and real foreign exchange earnings were the major determinants of demand for LPG. Price elasticity of LPG was inelastic) while kerosene was price elastic. The cross price elasticity of LPG and kerosene was positive, then, LPG was substitute fuel for kerosene. Besides, the study found that the existence of one unique co-integration relation between kerosene and LPG.

Nyembe (2011) tried to analyze the econometric analysis of factors determining charcoal consumption by urban households in Zambia. He found that households with old age heads were more likely to use charcoal than electricity. Female headed households were more likely to use charcoal than electricity consumption. He also tried to link between the level of education and energy types used and found that household head with high education level had higher probability of consuming clean fuel (electricity) than charcoal. According to him, household size had a positive effect on charcoal demand. Furthermore, the income elasticity of charcoal and electricity was +0.395 . The finding indicated that both energies were necessity good for urban Zambian households. He also found that households with refrigerator had less consumption of charcoal and electricity than households without refrigerators. Households with owning electric meter had less consumption of charcoal than households without electric meter owning.

Mekonen (2012) conducted research on impacts of rural electrification in Sub-Sahara Africa taking Ethiopia as a case. He tried to link the determinants of energy demand with accesses to electrification by using the logit model. According to his findings, fire wood consumption/expenditure was positively related to the consumption / expenditure of charcoal. He also identified household's preference to use firewood for injera baking complemented by BLT (Branches, leaves and twigs) and charcoal predominately used for coffee and tea making. The other findings like household total expenditure, occupation of households (business men against with farmers or civil servants) and family size positively affected the fire wood and charcoal consumption.

Nnaji, et,al.(2012) examined the determinants of household energy choices for cooking in Enugu state, Nigeria. They used Multinomial logit model to identify the main determinants of energy for cooking as well as sociological and economic variables influencing major energy sources in the area. From empirical findings, households' total income, the level of education of women, age of women, occupation of women and existence of internal cooking facilities were important factors that determine household cooking fuel choice.

Yonas, et.al. (2013) examined households' fuel choice in urban Ethiopia by using random effect multinomial logit analysis. In the study, they used panel data and tried to categorize the energy sources in three types. Solid for biomass, clean for modern and mix for both types of energy. Accordingly, several factors had been considered for the choice of these different energy categories in urban households in Ethiopia. Among these, fuel prices were important determinant of fuel choice. As the price of fire wood increased, the demand for solid and mixed fuels decreased. In other words, households tended to shift to clean fuel sources, such as, electricity and kerosene, when firewood price rose. They also examined the higher per capita expenditure (which is a proxy for per capita income) with the consumption of that energy in its category and found that have positive association with considering energy ladder hypotheses. Furthermore, the level of household head education was a strong determinant for fuel switching. Households head with high education level have large probability of using clean fuel sources and small chance of using solid fuels such as fire wood and charcoal.

From the forgoing discussion of empirical studies carried out in various countries by different scholars, different socio-economic variables have been identified as important variables affecting consumption of a particular fuel type. Demand for a particular type of energy depends on price, total expenditure and the household characteristics (family size, age of family head, level of education, gender, occupation, etc.). In different literatures, no standard rules were found for inclusion of household characteristics for demand analysis in different countries, despite their importance in shaping of household consumption behaviors. Thus, this study estimated household energy demand by considering the socio-economic of the households like price of energy, income of household, wealth, age of household, sex, size of household, education, owning of refrigerator, etc. 


\section{Method}

\subsection{The study area}

Addis Ababa is the largest city in Ethiopia with the total area of 54,000 hectares or $540 \mathrm{~km}^{2}$. The city lies on the altitude of 2,300 meters (7,546 feet) and located at $9^{\circ} 1^{\prime} 48^{\prime \prime} \mathrm{N}, 38^{\circ} 44^{\prime} 24^{\prime \prime} \mathrm{E}$ latitude. The city highest point is found at Entoto Mountain at 3,000 meters $(9,800 \mathrm{ft})$ above sea level in the north periphery. The lowest point is found around Bole International Airport, at 2,326 meters (7,631 ft) above sea level in the southern periphery (CGAA-BPACSP, 2010). Addis Ababa has a Subtropical highland climate zone, with temperature up to $10{ }^{\circ} \mathrm{C}$ differences, depending on elevation and prevailing wind patterns. The mean annual maximum and minimum temperature for Addis Ababa is $22.8 \mathrm{C}^{0}$ and $10.0 \mathrm{C}^{0}$, respectively. The mean annual rain fall is around $1,118.4 \mathrm{~mm}$ with the maximum of 132 rainy days per year (NMA, 2011).

According to 2007 Ethiopian census, Addis Ababa city population was estimated to be 2,739,551, of whom 1,305,387 were men and 1,434,164 were women. In the city, 662,728 households were living in 628,984 housing units, with average family size of 4.1 persons. The 2012 estimate of population of the city was 3,033,284 living within 739,829 households. The population density of the city was 5,617 persons per kilo meter square (CSA, 2008 and CGAA, 2013).

The residents of Addis Ababa use both modern and traditional energy sources for domestic energy activities. The sources are firewood, charcoal, animal dung, sawdust, barks, roots, leaves, kerosene, LPG and electricity (German Technical Cooperation-Sun (GTZ-Sun, 2010). Many factors were considered for selecting the study area. The key reasons for selecting Addis Ababa city are: steady growth of the population of the city, shortage of firewood, charcoal, kerosene and LPG, and the accompanying rise of their prices, and the sustainability challenges of energy supply. The other important energy feature of the city is that there are some peri-urban kebeles that have no access to electricity. In these places, there is less expansion of electricity grid, price fluctuation of different energy sources, and physical inaccessibility of kerosene and LPG.

There is also an increasing shortage of firewood in the city due to the imbalance between the supply and demand for the source due to depletion of the forest in the periphery of the city. The city is however still a good market for biomass energy supplies from its surroundings. Besides, the city is strategically located to access different kinds of energy sources like fire wood, charcoal, kerosene, LPG, electricity and even other varieties of energy sources like animal dung, leaves, barks, etc. The fact that the city is inhabited by people of different income groups make it's a market place for those kinds of energy.

\subsection{Data Sources}

The study used primary data that were collected from 466 households in 2012-13. The study employed a multistage stratified random sampling technique to identify data sources. The multistage random sampling technique is used for large scale enquiry covering large geographical area such as a state, large or medium city. Addis Ababa city is the largest city in Ethiopia and has ten sub cities and 116 urban and peri-urban woredas (CGAA, 2013). In the first stage of multi-stage sampling, sub-cities were selected randomly from stratified sub-cities, in the second stage woredas from each sub-city were selected randomly and finally households from each woreda were selected randomly.

For sampling purposes, the sub cities were categorized into two strata based on the following criteria: geographical location (distance from the center), boundaries with surrounding rural areas, size of geographical areas, population density and economic activities. Stratum one (outer sub cities) has six sub cities, namely, Gullele, Kolfe Keranyo, Nefas Silk, Akaki- Kality, Bole and Yeka. Those sub-cities with long distance from the center (Menilik II Square) border with rural areas in Oromia region, have large geographical areas, are sparsely to densely populated (on average 4,576 persons per $\mathrm{Km}^{2}$ ) and the major economic activities of the people are trade, services, transport, hotel, manufacturing, urban agriculture and animal husbandry.

Stratum two (inner sub-cities) has four sub cities that include Arada, Kirkos, Lideta and Addis Ketema. These four sub cities have short distance from the center, have no border with rural areas, have small geographical areas, are located relatively at the center of the city, densely populated with average of 35,795 Persons per $\mathrm{km}^{2}$, and the major economic activities of the people are trade, services, transport, hotel and tourism. After classifying the city into strata, three sub cities $(50 \%)$ were randomly selected from the first stratum, i.e. Gullele,Yeka and Akaki-Kality sub cities and two sub-cities (50\%) from second stratum - Arada and Lideta. After selecting the five sub cities, 50\% of woredas were also selected randomly from each selected sub-city. Accordingly, 26 woredas, 466 households were randomly selected from the sub-cities for the study. The number of sample households for each woreda is proportional to the respective woreda household population.

\subsection{Model Specification}

Consumer demand theory helps to describe the factors that determine the amount of income spent by the consumer on available goods and services. It determines the factors that influence consumer's decision together with consumer 
possibilities and behavior ( Theil, et.al., 1987). In demand theory, a consumer is assumed to have stable preference system which can be described by means of utility function. The basic assumption of it is a rational consumers always choose the most preferred bundle from a set of feasible alternatives to maximize their utility (Varian, 1992). In general, the consumer's demand for given commodities can be derived from utility maximization based on their budget constraints (Varian, 1992).

The economic theory of demand describes the energy demand by assuming that the households determine the energy type they prefer to use for cooking, heating or lighting on the basis of rational consideration. Hence, in our model specification, the demand is assumed to be determined by the socio-economic characteristics like price of energy, income of household, wealth, age of household, sex, size of household, education, frequency of cooking, household cooking practices in the kitchen, etc. Then, we used, AIDS model is used as the functional form specification to estimate household's energy demand in our study. It is written as

$$
\mathrm{W}_{\mathrm{ij}}=\alpha i+\sum_{j} \gamma i j \log p j+\beta i \log \left(\frac{m}{P}\right)+\varepsilon_{\mathrm{i}}
$$

Where: $\mathrm{W}_{\mathrm{i}}$ is the budget share of fuel ij from total expenditure or $\mathrm{p}_{\mathrm{i}} \mathrm{q}_{\mathrm{i}} / \mathrm{m}$

$\alpha_{i}$ is Intercept or a constant value which indicates that the average value of the budget share of fuel $i$ in the absence of price and income effects

$$
\begin{aligned}
& \gamma_{i j} \text { indicates the effects of price of fuel in group } j \text { on the budget share of fuel } i \\
& \beta_{\mathrm{i}} \text { indicates the effects of total energy expenditure on the budget share of fuel } i j \\
& \mathrm{P} \text { is a price index for energy group, } \\
& \mathrm{P}_{\mathrm{j}} \text { is the retail price of energy from } \mathrm{j} \text { groups and } \\
& \mathrm{m} \text { is total expenditure on fuels }
\end{aligned}
$$

Price index shows the current year's cost of particular baskets from the markets as a percentage of the cost of the same market in the same base year. A market basket is the combination of goods and services consumed by a typical family in a given period of time. The base year choice is assuming that year to be a normal economic year in terms of the country's economic environment in every aspect. E.g. the base year for Ethiopia of CPI was 2009 (CSA, 2012).

Price index can be estimated as

$$
\operatorname{loga}(\mathrm{p})=\Sigma \mathrm{jw}_{\mathrm{ik}} \log \mathrm{P}_{\mathrm{i}}
$$

Where: $\mathrm{w}_{\mathrm{ik}}$ stands for mean expenditure share on each energy sources from k types (firewood, charcoal, kerosene, LPg and electricity) and

$\mathrm{P}_{\mathrm{i}}$ stands the price of fuel $i$. Thus, the linear approximation to AIDS (LA-AIDS) model can be written as

$$
\mathrm{W}_{\mathrm{ij}}=\alpha i+\sum_{j} \gamma i j \log p j+\beta i \log \left(\frac{m}{\log a(p)}\right)+\varepsilon_{\mathrm{i}}
$$

NB. Equation (3) is linear-logarithmic or lin-log type of functional forms of the model. The lin-log model states that the absolute change in dependent variable (change in $\mathrm{W}_{\mathrm{i}}$ ) is equal to slope times the relative change in explanatory variables $\left(\mathrm{X}_{\mathrm{i}}\right)$.

Mathematically, $\Delta \mathrm{W}_{\mathrm{i}}=\beta_{\mathrm{i}}\left(\Delta \mathrm{X}_{\mathrm{i}} / \mathrm{Xi}\right)=$ absolute change in $\mathrm{W}_{\mathrm{i}}=\beta_{\mathrm{i}}$ (relative change in $\left.\mathrm{X}_{\mathrm{i}}\right)$

By considering the following three restrictions in AIDS model

$$
\begin{gathered}
\text { Adding up requires that all } \mathrm{j}: \sum_{i=1}^{n} \alpha i=1, \sum_{i=1}^{n} \beta i=0, \sum_{i=1}^{n} \gamma i=0 \\
\text { Homogeneity is satisfied if and only if, for all } \mathrm{i},: \sum_{i} \gamma i j=\sum_{j} \gamma i j=0, \\
\text { Symmetry requires that-: } \gamma i j=\gamma j i \text { for given } i, j \text { and } i \neq j
\end{gathered}
$$

Where: $i$ stand for each fuel type and $j$ represent price of each energy source in each equation

Provided that equations 4,5 and 6, equation (3) represents a system of demand function which add up to total expenditure $\left(\Sigma \mathrm{W}_{\mathrm{i}}=1\right)$, are homogeneous of degree zero in price and total expenditure that satisfy Slutsky Symmetry.

Given these, the AIDS model is simply interpreted as in the absence of changes in prices and real expenditure $(\mathrm{m} / \mathrm{p})$, the budget shares are constant and this is the natural starting point of using the model. Second, change in relative prices through the term $\gamma \mathrm{ij}$ : each $\gamma \mathrm{ij}$ represents 100 times of the effect on the ith budget share of a1\% increases in the jth with $(\mathrm{m} / \mathrm{p})$ hold constant. Then, Changes in real expenditure through the $\beta \mathrm{i}$ coefficient as $\beta \mathrm{i}>0$, the good is a luxury good, if 
$\beta \mathbf{i}<0$, the good is necessity good and if $\beta \mathbf{i}=0$, the good is an income independent( Deaton and Muellbauer,1980a and Gundimeda, et.al, 2006).

\subsection{Model Estimation}

To estimate the energy budget model, we estimated total energy expenditure as a function of total household expenditure. That means a linear relationship between the budget share of each good and the logarithm of total expenditure that also considers other socio-economic variables. It shows that the AIDS model has similar procedure with Engle expenditure model (Gundimeda, et.al., 2006).

Then, our model can be estimated as

$$
\mathrm{W}_{\mathrm{TEE}}=\alpha+\beta \log \mathrm{TE}+\Phi \mathrm{X}+\varepsilon
$$

Where: $\mathrm{W}_{\text {TEE }}$ is the share of household energy expenditure in the total expenditure, TE is Total Expenditure, $\mathrm{X}$ is vector of household characteristics, $\alpha, \beta, \Phi$, are parameters and $\varepsilon$ is an error term

These parameters are estimated by ordinary least square method by assuming that error terms are independently and identically distributed (iid). From this estimation, we estimated the income elasticity of energy demand by

$$
\eta i=1+\frac{\beta i}{w i}
$$

Where: $\eta$ i indicates the income elasticity, $\beta_{\mathrm{i}}$ represent estimated parameter and

Wi represents average energy expenditure and $\beta$ is parameter to estimated,

Interpretation: If $0<\eta \mathrm{i}<1$, the fuel $\mathrm{i}$ is classified as a normal good.

if $\eta \mathrm{i}<0$, the fuel $\mathrm{i}$ is classified as an inferior good.

If $\eta \mathrm{i}>1$, the fuel $\mathrm{i}$ is classified as a luxury good.

\section{Results and Discussion}

\subsection{Descriptive analysis of household energy demand}

The data indicates that, the average age of a household head is 47.33 years and the average family size is 4.49 . The family size of a household varies from one person to twelve persons. Besides, $74 \%$ of the sample households are male headed family while the remaining $26 \%$ of the households are female headed, $52.8 \%$ are women and $47.2 \%$ are male. Out of 466 households, $63.73 \%$ of the household heads are married. The remaining $15.23 \%$ of the household heads are widow, $13.52 \%$ of the household heads are single and $7.51 \%$ of the household heads are divorced. Regarding religion, $66.52 \%$ of the household heads are Orthodox Christians, $19.31 \%$ of the household heads are Muslim, 13.52\% of the household heads are Protestant, $0.63 \%$ of the household heads are Catholic and other religions followers. Looking their education level, $20.85 \%$ of the household heads are illiterate and a few that can read and write. The other $47.21 \%$ of the household heads have attained formal education from grade1-12 and the remaining 32.4\% of the household heads are above grade 12 or college graduates (Table 1).

Table 1. General characteristics of sample households (sample size $=466)$

\begin{tabular}{llrrrr}
\hline \multicolumn{1}{c}{ Variables } & & Mean & St.deviation & Min & Max \\
Age of Hh head & & 47.33 & 11.981 & 23 & 90 \\
Sex of Hh head (1 = male, 0 =female) & & 0.74 & 0.438 & 0 & 1 \\
Family size & & 4.493 & 2.127 & 1 & 12 \\
Share of male in hhs & & 0.473 & 0.009 & 0.455 & 0.492 \\
Share of female in hhs & & 0.528 & 0.009 & 0.51 & 0.547 \\
\hline & Item & & HCN & $\%$ \\
Marital status (\%) & Single & & $63 \mathrm{hhs}$ & $13.52 \%$ \\
& Married & & $297 \mathrm{hhs}$ & $63.73 \%$ \\
& Divorced & & $35 \mathrm{hhs}$ & $7.50 \%$ \\
Religion $(\%)$ & Widowed & & $71 \mathrm{hhs}$ & $15.24 \%$ \\
& Orthodox & & $310 \mathrm{hhs}$ & 66.525 \\
& Muslim & & $90 \mathrm{hhs}$ & $19.31 \%$
\end{tabular}




\begin{tabular}{llrr} 
& Protestant & $63 \mathrm{hhs}$ & $13.52 \%$ \\
& Catholic & $2 \mathrm{hhs}$ & $0.43 \%$ \\
Education level (\%) & Others & $1 \mathrm{hh}$ & $0.21 \%$ \\
& Illiterate, read and write & $105 \mathrm{hhs}$ & $20.38 \%$ \\
& Grade 1-4 & $42 \mathrm{hhs}$ & $9.01 \%$ \\
& Grade 5-8 & $76 \mathrm{hhs}$ & $16.31 \%$ \\
& Grade 9-12 & $102 \mathrm{hhs}$ & $21.89 \%$ \\
Households living in $(\%)$ & Above 12 grade & $151 \mathrm{hhs}$ & $32.40 \%$ \\
& Kebele or Housing agency & $199 \mathrm{hhs}$ & $42.70 \%$ \\
& Private own house & $168 \mathrm{hhs}$ & $36.05 \%$ \\
& Renting from private house & $59 \mathrm{hhs}$ & $12.66 \%$ \\
& Own condominium & $24 \mathrm{hhs}$ & $5.15 \%$ \\
& Residing with family & $16 \mathrm{hhs}$ & $3.43 \%$ \\
\hline
\end{tabular}

Source: Household survey, 2012/13.

Besides, the household energy use characteristics shows that the most chosen energy source for domestic activities (cooking, baking and heating except lighting) are charcoal (84.3\%), electricity (68.8\%), kerosene (62.3\%), firewood (56.6\%) and LPG (13.5\%). In the case of lighting, electricity is the only energy source for $99.3 \%$ households.

The survey result shows that, each household spends on average $14.7 \%$ or 376.98 birr per month of its expenditure for energy purchase. Out of this budget, 51.73birr is spent for firewood, 124.67 birr for charcoal, 80.28 birr for kerosene, 39.04 birr for LPG and 81.23 for electricity. The budget share of fire wood from the total energy expenditure is $14.4 \%$. While the other energy sources such as charcoal, kerosene, LPG and electricity are allocated $34.1 \%, 22.6 \%, 7.3 \%$ and $21.5 \%$ respectively. Household's total expenditure used as a general indicator level of household income. An average household's monthly expenditure is 2760.84 birr. From this, a household spends on average 376.98 birr for energy, 1,618.90 birr for food and 737.67 birr for other types of expenditure per month. In addition, Food expenditure takes $60 \%$, while other goods and services expenditure takes $25 \%$ and energy expenditure takes $15 \%$ from total share.

Out of 466 households, $70.3 \%$ of the households access electricity by their own electric meter. The remaining $29.7 \%$ of the households access electricity from their neighbors, families or from others. In the case of energy appliances, $46 \%$ of the households have refrigerator to cool or preserve their food for long time. $48 \%$ of the households use electric mitad for baking activities. The details are presented in table 2 .

Table 2. Households energy use with different characteristics (Sample size $=466$ )

\begin{tabular}{lrrrr}
\hline Variables & Mean & St.deviation & Min & Max \\
\hline Fire wood use $(1=$ Yes, $0=$ No) & 0.566 & 0.496 & 0 & 1 \\
Charcoal use $(1=$ Yes, 0=No) & 0.843 & 0.363 & 0 & 1 \\
Kerosene use $(1=$ Yes, $0=$ No) & 0.622 & 0.4853 & 0 & 1 \\
LPG use $(1=$ Yes, $0=$ No) & 0.135 & 0.3422 & 0 & 1 \\
Elec use for all except light $(1=$ Yes, $0=$ No) & 0.688 & 0.48 & 0 & 1 \\
Elec use only for lighting $(1=$ Yes, $0=$ No) & 0.993 & 0.08 & 0 & 1 \\
Fire wood expenditure in birr & 51.73 & 65.33 & 0 & 500 \\
Charcoal expenditure in birr & 124.67 & 72.81 & 0 & 400 \\
Kerosene expenditure in birr & 80.28 & 77.98 & 0 & 420 \\
LPG expenditure in birr & 39.04 & 112.46 & 0 & 600 \\
Electricity expenditure in birr & 81.23 & 67.24 & 0 & 400 \\
Budget share of firewood & 0.144 & 0.166 & 0 & 0.925 \\
Budget share of charcoal & 0.341 & 0.197 & 0 & 0.8 \\
Budget share of kerosene & 0.226 & 0.212 & 0 & 1 \\
Budget share of LPG & 0.073 & 0.019 & 0 & 0.857 \\
Budget share of electricity & 0.215 & 0.149 & 0 & 1 \\
Total Hhs expenditure /month & 2760.84 & 1233.11 & 690 & 7800 \\
Total food expenditure /month & 1618.9 & 722.29 & 100 & 4000 \\
Total other expenditure /month & 737.67 & 673.98 & 0 & 4000 \\
Total energy expenditure /month & 376.98 & 152.47 & 48 & 1110 \\
\hline
\end{tabular}




\begin{tabular}{lrrrr}
\hline Budget share of food & 0.599 & 0.137 & 0.04 & .903 \\
Budget share of others & 0.249 & 0.1424 & 0 & 0.943 \\
Budget share of energy & 0.147 & 0.0473 & 0.02 & 0.354 \\
Price of fire wood in birr/kg & 3.186 & 0.338 & 2.69 & 3.43 \\
Price of charcoal in birr $/ \mathrm{kg}$ & 4.616 & 0.725 & 3.75 & 5.56 \\
Price of kerosene in birr/liter & 14.213 & 0.569 & 13.8 & 15.15 \\
Price of LPG in birr/kg & 45.64 & 0.582 & 45 & 46.17 \\
Price of electricity in birr/kwh & 0.47 & 0.096 & 0 & 0.69 \\
Electric meter own & 0.706 & 0.455 & 0 & 1 \\
Refrigerator own & 0.461 & 0.499 & 0 & 1 \\
Electric Mitad own & 0.488 & 0.5 & 0 & 1 \\
Source: Household survey, 2012/13. & & & & \\
\hline
\end{tabular}

\subsection{Empirical analysis of household energy demand}

This section presents the empirical results of household energy demand made by the households to allocate their total expenditure on food, energy and other goods and services. In this analysis, energy expenditure share is determined as a function of total household expenditure and household characteristics like income, price, age, sex, marital status, religion, education, etc. Then, the model is written as follows WTEE $=\alpha+\beta \operatorname{logTE}+\Phi \mathrm{X}+\varepsilon$.

The Ordinary Least Square (OLS) method is used for regression analysis and as can be seen from finding, six variables are significant at $1 \%$, one variable at $5 \%$ and another one variable at $10 \%$ precision level. However, the cross sectional data with OLS model in our analysis has problem of heteroscedasticity. We used the Breusch-Pagan(BP) test for detecting heteroscedasticity. The BP test rejected the null hypothesis of homoscedasticity (constant variance in the $\mathrm{e}_{\mathrm{i}}$ ). Besides, multicollnearity is tested by the ${ }^{1}$ Variance inflating factor (VIF), ${ }^{2}$ Tolerance (TOL) test and Spearman's correlation coefficient of diagonal matrix for each energy demand model. Then, we found that the error terms have not constant variance in the regressions. Thus, OLS regression is no longer Best Linear Unbiased Estimator (BLUE) due to the presence of ${ }^{3}$ multicollnearity and ${ }^{4}$ heteroscedasticity .

Therefore, the Generalized Least Square (GLS) or Weighted Least Square estimation (WLS) is considered to solve or minimize the problems heteroscedasticity. The assumption in this case is the error terms are identically and independently distributed (iid). A WLS estimator is an estimator used to adjust for a known form of variance in error term and weighted by its standard deviation. It can be written as

$$
\mathrm{W}_{\mathrm{TEE}} / \delta=\alpha / \delta+\beta \log \mathrm{TE} / \delta+\Phi \mathrm{X} / \delta+\varepsilon / \delta
$$

Where: $\mathrm{W}_{\mathrm{TEE}}$ is the share of households energy expenditure in the total expenditure.

TE is total expenditure; $\mathrm{X}$ is vector of households' characteristics, $\delta$ is a standard deviation,

$\alpha, \beta, \Phi$, are parameters and $\varepsilon$ is an error term.

NB: the standard deviation $(\delta)$ is calculated from either from dependent variable, independent variables or both variables variance. The average standard deviation of the dependent and one randomly selected explanatory variable (log family size) is taken to bring representative or optimal result for energy model. Their average standard deviation is 0.141 .

Table 3. The mean and standard deviations of energy budget share and family size

\begin{tabular}{lllll}
\hline Variables & Observation & Mean & Std.err & Std.dev \\
Energy budget share $(\%)$ & 466 & 0.1469 & 0.0022 & 0.0473 \\
Log Family size & 466 & 0.5965 & 0.0109 & 0.2367 \\
Average & 466 & 0.3717 & 0.0066 & 0.1411 \\
\hline
\end{tabular}

\footnotetext{
1 Variance inflating factor measures the speed with which variance and covariance increase. It is computed as VIF $=\frac{1}{1-r 2}$, Where: $r^{2}$ is Correlation Coefficient, it means a measure of linear association or dependence between two random variables, which does not depend on units of measurement and is bounded between -1 and $1 . \quad \mathrm{VIF}=1.75, \mathrm{r}^{2}=0.43$,

All Spearman's correlation coefficients are below 0.8 .

2 TOL $=1 /$ VIF or $1-r^{2}=1 / 1.75=0.57$

${ }^{3}$ Multicollinearity means the existence of perfect or exact linear relationship between two or more explanatory variables in the regression model.

4 The probability distribution of random variables $\left(u_{i}\right)$ is the same over all observation of $x$, and in particular that the variance of each $u_{i}$ is that same for all values of the explanatory variables $\operatorname{Var}\left(\mathrm{u}_{\mathrm{i}}\right)=\mathrm{E}\left\{\left(\mathrm{u}_{\mathrm{i}}-\mathrm{E}\left(\mathrm{u}_{\mathrm{i}}\right)\right\}^{2}=\mathrm{E}\left(\mathrm{u}_{\mathrm{i}}\right)^{2}=\delta^{2}=\right.$ Constant variance
} 
Source: Own computation

After estimating the average of standard deviation, transforms the WLS equations in to

$\mathrm{W}_{\mathrm{TEE}^{*}}=\alpha^{*}+\beta \log \mathrm{TE}^{*}+\Phi \mathrm{X}^{*}+\varepsilon *$ and assume that $\varepsilon$ and $\mathrm{u}$ are interchangeable variable

The variance of error term can be as $\operatorname{Var}\left(\mathrm{u}_{\mathrm{i}}{ }^{*}\right)=\mathrm{E}\left\{\left(\mathrm{u}_{\mathrm{i}}{ }^{*}-\mathrm{E}\left(\mathrm{u}_{\mathrm{i}}{ }^{*}\right)\right\}^{2} \mathrm{r}=\mathrm{E}\left(\mathrm{u}_{\mathrm{i}}{ }^{*}\right)^{2}=\mathrm{E}\left(\mathrm{u}_{\mathrm{i}} / \delta^{2}\right)^{2}\right.$

$\operatorname{Var}\left(\mathrm{u}_{\mathrm{i}}{ }^{*}\right)=\frac{1}{\delta 2} \mathrm{E}\left(\mathrm{u}_{1}{ }^{2}\right)$ since $\delta^{2}$ is un-known. I.e. in our case the variance is 0.0198 and Standard deviation is equal to 0.141 .

Finally, we regress the transformed equation by weighted least square to minimize a weighted sum of Residual Square by $1 / \delta^{2}$. But, in OLS, the residual sum square is un-weighted. So,

$$
\begin{array}{r}
\operatorname{Var}\left(\mathrm{u}_{\mathrm{i}}^{*}\right)=\frac{1}{\delta 2}\left(\delta^{2}\right), \quad \text { since } \mathrm{E}\left(\mathrm{u}_{1}^{2}\right)=\delta^{2} \\
\operatorname{Var}\left(\mathrm{u}_{\mathrm{i}}^{*}\right)=1 / 0.0198(0.0198) \\
\operatorname{Var}\left(\mathrm{u}_{\mathrm{i}}^{*}\right)=1=\text { which is constant. }
\end{array}
$$

The variance of $\left(u_{i}{ }^{*}\right)$ is now homoscedastic. i. e. have constant variance. In short, GLS or WLS is OLS on the transformed variables that satisfy the standard least square assumptions and the estimators are BLUE (Best Linear Unbiased Estimators (Koutsoyiannis, 2008).In the regression, some coefficients are not found to be significant in the estimation of OLS and turned out to be significant(age, marital status and religion) in WLS estimation. The results of

\begin{tabular}{|c|c|c|c|c|}
\hline Wtee & Coef. & Std. Err. & T-value & $\mathbf{P}>\mathbf{t}$ \\
\hline Age $(\log )$ & 0.0234 & 0.0079 & 2.96 & 0.003 \\
\hline $\operatorname{Sex}(1$ if male headed hh, 0 ,otherwise) & -0.0225 & 0.0025 & -9.21 & $0.000 * * *$ \\
\hline Women share in \% & -0.0024 & 0.003 & -0.8 & 0.426 \\
\hline Family size $(\log )$ & -0.0476 & 0.0052 & -9.11 & $0.000^{* * *}$ \\
\hline Marital status( 1 if married, 0 otherwise) & 0.01 & 0.0022 & 4.5 & $0.000^{* * *}$ \\
\hline Religion(1 if Christian, 0 otherwise) & 0.0055 & 0.0019 & 2.94 & $0.003 * * *$ \\
\hline Hhs head education level ( 1 if Post- Primary) & -0.0027 & 0.0018 & -1.45 & 0.147 \\
\hline $\begin{array}{l}\text { Hhs head education level }(1 \quad \text { if } \\
\text { Post-Secondary) }\end{array}$ & 0.012 & 0.0019 & 6.03 & $0.000 * * *$ \\
\hline Own house( 1 if own, 0 otherwise) & -0.0023 & 0.0017 & -1.37 & 0.17 \\
\hline Own electric meter( 1 if own, 0 otherwise) & 0.0156 & 0.0019 & 8.34 & $0.000^{* * *}$ \\
\hline Own refrigerator ( 1 if own, 0 otherwise) & -0.0126 & 0.002 & -7.34 & $0.000 * * *$ \\
\hline Total energy expenditure(birr)per month(log) & 0.1131 & 0.0063 & 17.81 & $0.000 * * *$ \\
\hline Total expenditure(birr)per month(log) & -0.0568 & 0.0023 & -25.18 & $0.000^{* * *}$ \\
\hline _constants & 0.0279 & 0.0207 & 1.35 & 0.178 \\
\hline $\mathrm{F}(13,452)=104.76^{* * *}$, Prob $>\mathrm{F}$ & $=0.0000, \mathrm{R}^{2}$ & $=0.750$ & Adj $R^{2}=0.741$ & \\
\hline
\end{tabular}
WLS estimations are presented in table 4 as follows

Table 4. First stage budget estimation by Weighted Least Square $(\mathrm{N}=466)$

***represents significance at $1 \%, * *$ significance at $5 \%$ and $*$ significance at $10 \%$.

Std. Err is Robust Standard error or heteroscedasticity corrected standard error

Source: Household survey, 2012/13.

In the linear-logarithmic (lin-log) regression model, the slope of coefficient measures the absolute change in the dependent variable for a relative change in the explanatory variables. From the regression result, the direction of coefficients is in line with our expectation. From our expectation, the age of family head positively and significantly affects allocation of energy budget i.e. as households head become older; more budgets is allocated for different fuels, perhaps due to use more fuel than the younger family head since old age family may have large family member than the young. In our analysis we found out that when the age of a family head increases by one more year, keeping all other 
variables constant, the energy budget share increases by $2.3 \%$. i.e. $(0.023 * 100)$. The finding is consistent with the works of Chambewera (2004), Zenebe (2007), Alemu, et, al. (2008) and Nyembe (2011).

Family size negatively and significantly affects allocation of energy budget .i.e. as household family size increases; the household allocates less proportion of his /her budgets for energy. As households family size increases by one more member, keeping all other variables constant, the proportion of energy budget share declines by $4.7 \%$. This may be due to the exploitation of economies of scale associated with relatively less per capita energy demand for larger household family size. That means additional family members' benefits from the fuel consumption of other members result in using improved stove for domestic energy activities. And also, when the use of modern energy for daily cooking becomes too costly, then the households reallocate the energy budget to cheaper one (such as fire wood and charcoal).

The sex of household head negatively affects allocation of energy budget. It indicates that the male family headed expends less than female head households. As households headed by male, keeping all other variables constant, the energy budget share declines by $2.2 \%$. This can be due to the male headed households probably that prefer the cheapest energy sources like traditional fuel type compared to female headed households and that males are mostly worry about the quantity of energy than quality, and that female heads are mostly concerned about the quality than the quantity of different types of energy. The two findings are in line with the works of Zenebe (2007), Samuel (2008), Nyembe (2011) and Yonas, et.al.(2013).

The marital status of a family head positively and significantly affects the allocation of energy budget. The result from this study indicates that the married households allocate more for energy budget than unmarried families. If household become married, all other variables held constant, the energy budget share increases by $1 \%$. The reasons behind this is that more energy is used by married households than un married and the married households have naturally more family members thus use more energy than not married households. The result is in agreement with the works of Chambwera (2004), Ouedraogo (2006) and Neyembe (2011).

The level of education of the household head positively and significantly affects allocation of energy budget. It means, when households head who attends at post-secondary level of education, expend more energy budget for energy. When the level of education of household head increases to post-secondary level, keeping all other variables constant, the energy budget share increases by $1.2 \%$. It indicates that educated households use more modern and expensive energy sources for their domestic energy consumption. Whereas, the less educated households head prefer more traditional and cheap energy type. It is similar finding with Chambwera(2004), Zenebe (2007), Alemu,et,al.(2008), Nyembe (2011) and Yonas, et.al. (2013).

Owning of a refrigerator is inversely related with budget share of energy. As household's probability to own refrigerator increase, keeping all other variables constant, the energy budget share decreases by $1.2 \%$. It indicates that, the households that have their own refrigerator, prepares more foods at once and preserve for long time in their refrigerator and reducing cooking frequency. Hence, less cooking frequency for food preparation may lead to less energy expenditure than households with more cooking and with no refrigerator. The result is also similar to the findings of Hydy, et, al. (2000), Ouedraogo (2006) and Neyembe (2011).

The owning of other electric appliances like electric meter also has positive relationship with energy budget share. It means, if the households have their own electric meter at home, keeping other variables constant, the energy budget share also increases by $1.5 \%$. This can be due to households do not have electricity shortages for different energy purposes like baking, cooking, heating, lighting than the households who do not have their own electric meter at home. It is coincided with the finding of Ouedraogo (2006) and Nyembe (2011).

Total household expenditure and energy budget share are negatively related. It indicates that, as households expenditure rise, the energy budget share tends to decline. Most importantly the coefficient of household's total expenditure shows the nature of energy goods but not the magnitude of the changes (Gundimeda, et, al.2006). The negative sign shows the energy is a necessity good for households. To measure the actual changes of demand when households total expenditure change, the income elasticity of demand is computed.

Income elasticity is a measure of consumers' relative responsiveness to income changes. Table, 4.9 shows that, the expenditure elasticity of energy demand in the first stage budget estimation is 0.61 .It means that, as a $1 \%$ increase in the total household expenditure, demand for energy increases by $0.61 \%$. The result shows that, energy is a necessity good for city households. It is coincided with the work finding of Chambwera (2004), Zenebe (2007), Alemu,et,al. (2008) and Nyembe (2011) works. 
Table 5. Income or expenditure elasticity from $1^{\text {st }}$ stage budget estimation $\left(\eta \mathrm{if}=1+\left(\beta_{\mathrm{i}} / \mathrm{w}_{\mathrm{i}}\right)\right)$

\begin{tabular}{lccc}
\hline Coefficient & $\mathrm{Bi}$ & Mean energy expenditure share & Income elasticity \\
Value & -0.057 & 0.147 & 0.61 \\
\hline
\end{tabular}

Source: Own computation

\subsection{Evaluation of Energy Demand Model}

In Weighed Least Square analysis, the overall significance test of the model, F-test, is computed to be F(13,452) $=104.76(0.000)$ ( (Table 4) which is statistically significant indicating that the given predictor variables in the model are collectively important and explain the behavior of household energy demand in Addis Ababa city. In addition, the Coefficient of determination or $\mathrm{R}$-square value is 0.75 which indicates that the model explained about 75 percent of the energy demand model.

\section{Conclusion}

In Addis Ababa city, each household spends on average $14.7 \%$ or 376.98 birr per month of its expenditure for energy purchase from their total expenditure. Energy is a necessity good for city households and has positive income elasticity (0.61). And, household size, the proportion of women in households, household head level of education, owning of dwelling and electric appliance (electric meter and refrigerator) are important factors that affect the decision to use energy. The main findings imply the importance of enhancing households' income, education, promoting education, ownership of electric meter and other energy appliances like refrigerators are instrumental variables for households to increase household modern energy demand and reduce energy poverty for city households.

Thus, Encouraging households to adopt energy appliances like refrigerator for domestic energy activities by subsidizing the appliance or promote to produce or assemble locally. It enables to save households time, energy expense and energy. This helps to reduce energy poverty at household's level. Promoting supply of alternative energy sources such as solar and wind energy beside hydroelectricity. As it enables to create more access to clean energy sources, supply those energies at low price and promote to use different energy appliances. And, improving per capita income of households by expansion and creating more job opportunities city population. It enables to consolidate the economic power of individuals, use more modern energy sources than traditional ones, adopt different energy appliances and reduce energy poverty at household level.

\section{References}

Alemu, M., \& Koholin, G. (2008). Determinants of Household Fuel Choice in Major Cities in Ethiopia. Environment for Development: Discussion paper series, EfD-DP-08(18), 1-23.

Asmerom, K. (1991). Demand for Energy in Rural and Urban Centers for Ethiopia: An Econometric analysis. Energy economics, 13(2), 130-134.

Bereket, K., Almaze, B., \& Elias, K. (2002). Can the Urban Poor afford Modern Energy? The Case study of Ethiopia. Energy policy paper, 30, 1029-1045.

CGAA (2013). Annual Reports on Socio-Demographic Situation of Addis Ababa city, Vol-1, Addis Ababa, Ethiopia.

CGAA-BOFED (2013). Regional Gross Domestic Products for Addis Ababa City Administration. Addis Ababa, Ethiopia.

CGAA-BPACSP (2010). Atlas of Key Demographic and Socio -Economic indicators of Addis Ababa in 2010.Addis Ababa, Ethiopia.

Chambwera, M. (2004). Economic Analysis of Urban Fuel Demand: The Case Study of Harare in Zimbabwe. $\mathrm{PhD}$ dissertation, Wageningen University, Netherlands, ISBN-90-8504-0868.

CSA (2008). Ethiopian 2007 Population Census Final Report. Addis Ababa, Ethiopia.

CSA (2010). Ethiopian 2007 Population Census Summary Report. Addis Ababa, Ethiopia.

CSA (2012). Ethiopian Welfare Monitoring Survey in 2011. Summary Report, Addis Ababa, Ethiopia.

Dattalo, P. (2008). Determining Sample Size: Balanced power, Precision and Practicality. Oxford University Press.

Deaton, A., \& Muellbauer, J. (1980a). An Almost Ideal Demand System. The American Economic Review, 70(3), 312-326. 
Deaton, A., \& Muellbauer, J. (1980b). Economics and Consumer Behavior. Cambridge University Press, New York, USA.

DGEP (2011). Access to Different Energy Sources for Developing Countries in European Parliaments, Expo/b/deve/2011/19.

EPA (2012). National Report of Ethiopia: United Nations Conference on Sustainable Development (Rio+20), Addis Ababa, Ethiopia .

ESCAP (2012). Widening Energy Access and Enhancing Energy Security to Achieve the Millennium Development Goals in Asia and the Pacific. Energy Resources Development Series, 42, Thailand.

ESMAP (2000). Energy and Development Report 2000: Energy Services for the World's Poor. Washington DC., USA.

ESMAP (2003). Household Fuel Use and Switching in Guatemala. Joint publication by UNDP and World Bank Energy Sector Management Assistance Program. Washington DC, USA.

Getamesay, B. (2011). Determinants of Kerosene and LPG Demand in Ethiopia. Msc thesis prepared in 2007 and published by VDM Publishing House Ltd, Amazon distribution GmbH, Leipzig, ISBN: 978-3-639-32675.

Goldemberg, J. (1990). One kilowatt per Capita. Bulletin of the Atomic Scientists, 46(1), 12-26.

GTZ-Sun (2010).Household Energy Base line Survey in Addis Ababa, Addis Ababa, Ethiopia.

Gundimeda, H., \& Khollin, G. (2006). Fuel Demand Elasticity's for Energy and Environmental Policies for Indian Sample Survey Evidences. Working paper No, 9/2006, India.

Heltberg, R. (2003). Fuel Switching: Evidence from Eight Developing Countries. Energy Economics, 26(5), 869-887.

Hydy, W., \& Kholin, G. (2000). Social Forestry Reconsidered. Energy policy, 34(3), 285-314.

IEA (2010). World Energy Outlooks. Paris, France.

Kemmler, A. (2007). Characteristics of Energy Access to Poor and Impoverished Regions in India. Phd dissertation, 17033, Zurich, Switzerland.

Kothari, C. (2000). Research Methodology: Methods and Techniques. Published by K.k Gupta, New Age International Private limited, New Delhi.

Koutsoyiannis, A. (2008). Theories of Econometrics: An Introductory Exposition of Econometric Methods. Second Edition, Published by Palgrave, New York, USA.

Leach, G. (1987). Household Energy Hand Book. An International Guideline and References Manual 67. World Bank, Washington DC., USA.

Leach, G. (1992). The Energy Transition. Energy Policy, 20(2) 116-123.

Masud, J., Sharan, D., \& Lohani, B. (2007). Energy for All: Addressing the Energy, Environment, and Poverty nexus in Asia. Asian Development Bank, Philippines.

Mekonen, L. (2012). Assessing the Impacts of Rural Electrification in Sub-Saharan Africa: The Case of Ethiopia. PhD dissertation, University of Victoria.

Modi, V., \& Goldemberg, J. (2005). Energy Services for MDGs. Jointly Published by World Bank and UNDP, New York, USA.

NMA (2011). National Meteorological Agency of the Federal Democratic Republic of Ethiopia. Annual report for Meteorology in 2010. Addis Ababa, Ethiopia.

Nnaji, C., Ukwueze, E., \& Chukwu, J. (2012). Determinants of Household Energy Choices for Cooking in Enugu state, Nigeria. National Centre for Energy R \& D and Department of Economics, University of Nigeria. Nsukka Continental J. Social Sciences, 5(2), 1-11.

Nyembe, M. (2011). An Econometric Analysis of Factors Determining Charcoal Consumption by Urban Households: The case of Zambia. Thesis No, 641, ISSN 1401-4084, Uppsala, Swedish University of Agricultural Science.

Ouedraogo, B. (2006). Household Energy Preferences for Cooking in Urban Ouagadougou: Burkina Faso. Energy policy, 34, 3787-3795.

Samuel, F. (2008). Household's Consumption Pattern and Demand for Energy in Urban Ethiopia. Addis Ababa 
University, Ethiopia.

Theil, H., \& Clements, W.(1987). Applied Demand Analysis Results from System Wide Approaches. Cambridge University Press.

UNDP. (2009). The Energy Access Situation in Developing countries. A Review of Focusing on Least Developed Countries and Sub Saharan Africa. New York, USA

UNDP. (2013). The Rise of the South, Human Progress in a Diverse World. Published for the United Nations Development Program. ISBN 978-92-1-126340-4, New York, USA.

Varian, H. (1992). Advanced Micro Economic Analysis. Third Edition, Norton Company, USA.

WEO. (2004). Energy and Development Measurement Methodology. Chapter 10:329-362. Retrieved from http://www.worldenergy outlook.org/development on the date of Nov 25/2012.

World Bank (2000). Fuel for Thought: Environmental Strategy for Energy Sector. Washington DC., USA.

World Bank (2011a). Household's Cook stoves, Environment, Health, and Climate Change: A New Look at Old Problem. World Bank, Washington DC., USA.

Yonas, A., Abebe, D., Köholin, G., \& Alemu, M. (2013). Household Fuel Choice in Urban Ethiopia: A Random Effects Multinomial Logit Analysis. Environment for Development, EfD -DP, 13(12), 1-31.

Zenebe, G. (2007).Household Fuel Consumption and Resource use in Rural-Urban Ethiopia: The Case study of Tigray region. $\mathrm{PhD}$ dissertation, Wageningen University, Netherlands.

\section{$(\mathrm{cc}) \mathbf{E Y}$}

This work is licensed under a Creative Commons Attribution 3.0 License. 